\title{
DEL GENIO A LAS INDIAS: MEDALLAS Y MONEDAS PROCLAMARON NUEVOS GOBIERNOS EN COSTA RICA (1821-1850)
}

\author{
FROM THE GENIE TO THE INDIANS: MEDALS AND COINS \\ PROCLAIMED NEW GOVERNMENTS IN COSTA RICA (1821-1850)
}

\author{
José A. Vargas Zamoral \\ jose.vargas@ucr.ac.cr \\ Manuel B. Chacón Hidalgo ${ }^{2}$ \\ chaconhm@bccr.fi.cr
}

Fecha de recepción: 13 de noviembre de 2015 - Fecha de aceptación: 23 de mayo de 2016

\begin{abstract}
Resumen
La independencia del gobierno español decretada por Guatemala en 1821 fue conmemorada con la emisión de una medalla en la que el genio de la libertad separa al Nuevo Mundo del Viejo. En 1822 la proclamación de Agustín I como emperador también fue divulgada con la producción de medallas en las ciudades de Chiapas, Guatemala, León, y tal vez en Cartago. Las medallas de proclamación eran una tradición traída de España al Nuevo Mundo y su emisión era acompañada de ceremonias y festejos bajo un protocolo complejo. Este trabajo aporta información sobre el significado de las figuras grabadas en medallas y monedas emitidas entre 1821 y 1850. Además, se incluyen datos sobre la primera moneda conmemorativa de Costa Rica que proclamó la Constitución de 1847, así como de las emisiones asociadas a la fundación de la República de Costa Rica en 1848. Se enfatiza el hecho de que las monedas y medallas servían también como medios de propaganda para un público que en su mayoría no tenía acceso a medios de comunicación escritos, o era analfabeto.

Palabras clave: Constitución de 1847, reales de plata, mariquitas, Iturbide, café
\end{abstract}

\begin{abstract}
Independence from the Spanish government was decreed by Guatemala in 1821 and commemorated by the release of a medal on which the genie of liberty separates the New from the Old World. In 1822 the proclamation of Agustín I $I^{\circ}$ as emperor was also made known by the production of medals in the cities of Chiapas, Guatemala, León, and perhaps in Cartago. Proclamation medals were a tradition brought from Spain to the New World and were accompanied by ceremonies and festivities under a complex protocol. This work provides information on the meanings of the figures engraved on medals and coins issued between 1821 and 1850. It also includes data on the first conmmemorative coin of Costa Rica, which proclaimed the Constitution of 1847, as well as on the issues related to the foundation of the Republic of Costa Rica in 1848. It emphasizes the fact that coins and medals also served as means of propaganda for a public that in general lacked access to printed information or was illiterate.
\end{abstract}

Key words: Constitution of 1847 , silver reales, mariquitas, Iturbide, coffee.

1 Escuela de Biología, Sede Rodrigo Facio, Universidad de Costa Rica.

2 Museo de Numismática del Banco Central de Costa Rica. 


\section{Introducción}

El 15 de setiembre de 1821 Guatemala decretó su independencia del gobierno español y un acta manuscrita fue levantada, cuyo Artículo 18 (Anónimo, 1948, p. 3), dice:

\footnotetext{
Que imprimiéndose ésta acta, y el manifiesto expresado se circule a las Excmas. Diputaciones provinciales, Ayuntamientos constitucionales, y demás autoridades eclesiásticas, regulares, seculares, y militares para que siendo acordes en los mismos sentimientos que ha manifestado este Pueblo, se sirvan obrar con arreglo a todo lo expuesto...
}

En cumplimiento de ese artículo y con fecha 16 de setiembre de 1821 fueron elaboradas en Guatemala copias impresas de la transcripción del Acta para ser enviadas a diversas autoridades en Guatemala y en el exterior. En la versión manuscrita (Anónimo, 1948) hubo un error en la numeración (ya anotado por Lines, 1971) y se pasó del numeral $8^{\circ}$ al $10^{\circ}$. Este error fue corregido en la versión impresa. Una (o varias según se deduce del Artículo 18) de esas copias impresas llegaron a Cartago desde León a mediados de octubre de 1821. Sin embargo, el Archivo Nacional de Costa Rica conserva solo un ejemplar (A.N.C.R., Provincial Independiente 121).

Recientemente, un coleccionista nos facilitó otra copia, la que consideramos auténtica, pues está impresa por ambas caras en tres columnas de $120 \mathrm{~mm}$ de ancho (con márgenes libres de 45 a $50 \mathrm{~mm}$ a ambos lados), en un pliego de papel de 430 x $314 \mathrm{~mm}$, con marca de agua y sello de seguridad CAPE$L L A D E S$ visible a contra-luz. El pliego aparece doblado a la mitad y no tiene agujeros que evidencien haber formado parte de un libro cosido a mano.

En el Artículo 17 del Acta manuscrita (Figura 1A) y en el 16 de la versión impresa (Figura 1B) se acuerda ("disponga" en la manuscrita) que se acuñe una medalla alusiva al acontecimiento. Ese

A

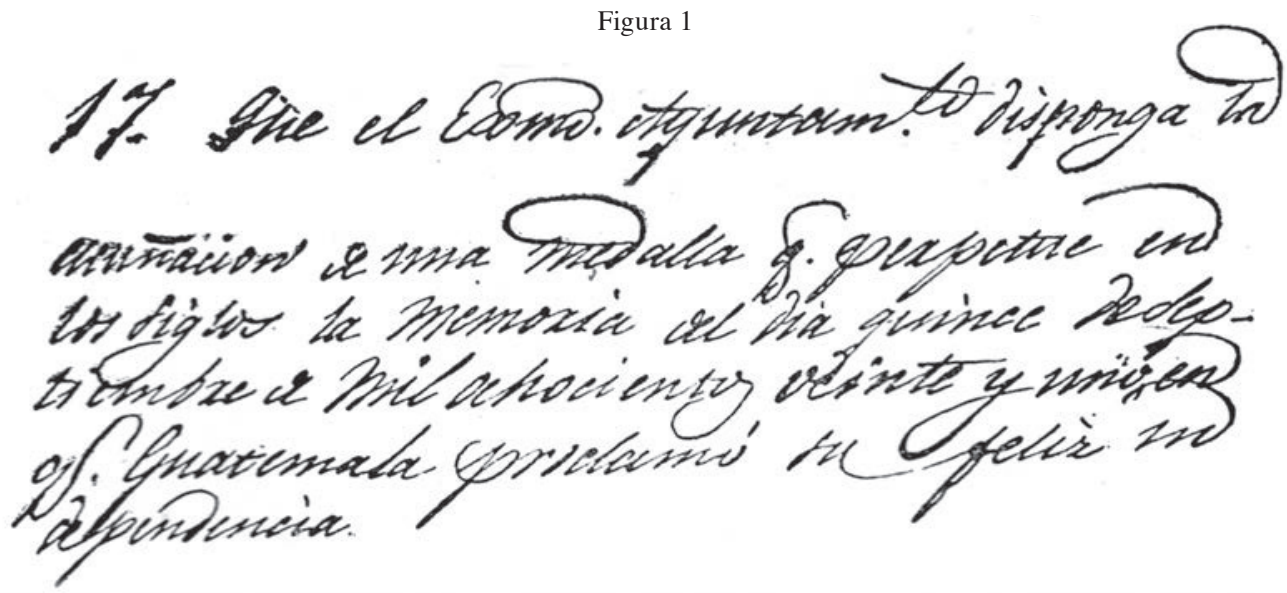

16. Que el Excmo. Ayuntamiento acuerde la acuñacio de una medalla que perpetúe en los siglos la memoria del dia QUINCE DE SEPTIEMBRE DE MIL OCHOCIENTOS VEINTE Y UNO, en que proclamó su feliz independencia.

Versiones de un artículo del Acta de la Independencia de Guatemala (1821). A. Artículo 17 (según fascímil de 1948) del Acta manuscrita el 15 de setiembre de 1821 (...que el Excmo. Ayuntamiento disponga la acuñación de una medalla). B. Artículo 16 de la copia (colección privada) del Acta impresa el 16 de setiembre de 1821 (...que el Excmo Ayuntamiento acuerde la acuñación de una medalla...). Nótese que en el texto impreso se omite la palabra Guatemala. 
artículo destaca por su originalidad y el producto de su cumplimiento fue la emisión de la medalla conmemorativa de la independencia de Guatemala.

Según Lines (1971) el 16 de setiembre de 1821 el Cabildo de Guatemala dispuso que: "en señal de regocijo se bata moneda de la corriente en cantidad de trescientos pesos que han de prepararse en cuatro azafates de plata para que se arrojen al pueblo" También se acordó acuñar moneda por igual monto y que tuviera grabado el símbolo de libertad más expresivo. Probablemente, esa acuñación no se llevó a cabo debido a lo convulso de los acontecimientos políticos que siguieron.

La producción de medallas alusivas a acontecimientos políticos relevantes, así como la acuñación de monedas de tipo conmemorativo y de tipo normal fueron instrumentos importantes de comunicación desde tiempos antiguos. Además de servir como medio de pago, las monedas y medallas funcionaban para proclamar formas de gobierno y prioridades gubernamentales a través de los símbolos grabados en ellas, pues ante la escasez o falta de periódicos y la abundancia de analfabetos, las figuras grabadas en esas piezas metálicas eran entendibles por la mayoría.

El objetivo de este escrito es aportar reflexiones sobre algunas piezas producidas en Guatemala y en Costa Rica en la primera mitad del siglo XIX (1821-1850) y los mensajes implícitos o explícitos que se proclamaron a través de ellas.

\section{La medalla de Guatemala, 1821}

El acuerdo para la acuñación de una medalla alusiva a la independencia de Guatemala fue cumplido tiempo después. Los documentos de la época indican que se acuñaron escasos ejemplares en oro y un total de 100 copias en plata (903 milésimas de plata pura), las que fueron distribuidas el 3 de octubre de 1822 en medio de una sociedad dividida entre los a favor de la anexión a México y los independentistas. De acuerdo con Lines entre los independentistas estaba don Pedro Molina, autor del lema de la medalla: "el libre ofrece paz pero el siervo jamás". Las 100 piezas de plata tuvieron un costo total de 153 pesos.

Los troqueles de la medalla fueron grabados en Guatemala por José Casildo España (J.C.E., en la medalla) y las medallas fueron acuñadas posiblemente en México, pues las letras: 'Mo' que identifican a la ceca de la ciudad de México están grabadas en uno de los pilares. En la Figura 2 hemos incluido la imagen de una de estas medallas, de la cual interesa resaltar dos aspectos:

\section{Figura 2}
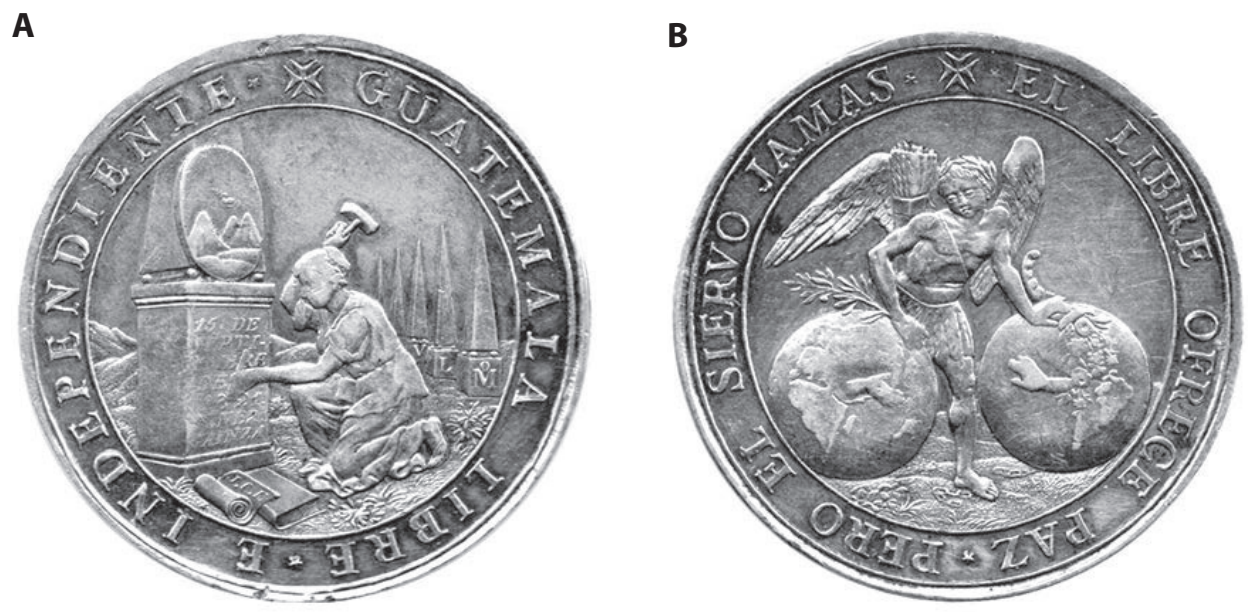

Anverso (A) y reverso (B) de la medalla con- memorativa de la independencia de Guatemala (1821 acuñada en México en 1822. Diámetro $43 \mathrm{~mm}$, peso $41.7 \mathrm{~g}$, plata 903/1000. Una escultora graba la fecha de la independencia en el pilar que exhibe el escudo de Antigua Guatemala. El genio de la libertad, vestido con una faldilla que representa al indígena americano, separa al Nuevo Mundo del Viejo. 
Primero: En el anverso (Figura 2A) aparece una figura que, contrario a la opinión de Lines, nos parece femenina por su vestimenta, el lazo que le sostiene atrás el cabello y la silueta del pecho derecho. Ella representaría entonces a Guatemala, quien graba la fecha de su independencia en el pilar que sostiene el escudo de la ciudad de Antigua Guatemala. Detrás de la escultora hay una fila de cinco pilares, los que según Lines simbolizan a las cinco provincias remanentes del antiguo orden: Guatemala, Honduras, El Salvador, Nicaragua y Costa Rica. Sin embargo, en 1812 y 1820 hubo reorganizaciones administrativas de la región y en 1821 los territorios involucrados eran: Chiapas, Guatemala, Honduras, El Salvador, Nicaragua, el Partido de Nicoya y Costa Rica.

Por lo tanto, no parece lógico que Guatemala esté representada por dos pilares. Surge entonces la posibilidad de que el primer pilar le corresponda a Chiapas, predecesor de la independencia y cuya anexión definitiva a México ocurriría en 1823. Honduras, El Salvador, Nicaragua y Costa Rica estarían representados por los pilares restantes. Cabe preguntarse si en el diseño de la medalla se ignoró el hecho de que Nicoya tenía categoría de Partido con cierta autonomía. Entonces, otra posibilidad es que los cinco pilares correspondan a: Chiapas, Honduras, El Salvador, Nicaragua-Costa Rica (con sede en León) y el Partido de Nicoya (que se anexaría a Costa Rica por decisión propia en 1824). No hay certeza sobre el significado de las letras: 'L' y ' $V$ ' grabadas en el segundo y tercer pilares, respectivamente

Segundo: El reverso (Figura 2B) alude según Lines a las monedas coloniales conocidas como: dos mundos o columnarias emitidas por varias cecas latinoamericanas a partir de 1732 (México) y hasta 1772, cuando Carlos III dio orden de que en adelante su efigie fuera grabada en todas las monedas. Este cambio de diseño hizo posible que la apariencia del rey fuera conocida en todo el imperio. En las columnarias (Figura 3) el imperio español está representado por dos hemisferios unidos bajo una corona y el lema: "VTRAQUE VNUM" (somos uno). Asimismo, a los costados de los hemisferios hay sendas columnas que representan, según la mitología griega, a las de Hércules en la entrada del mar Mediterráneo En ellas hay cintas que llevan escrita la leyenda "PLUS ULTRA" (más allá).

Figura 3

A

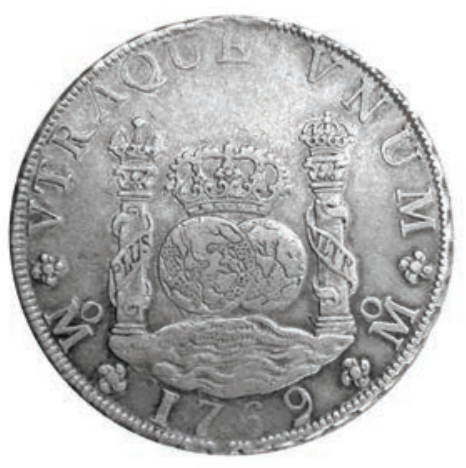

B

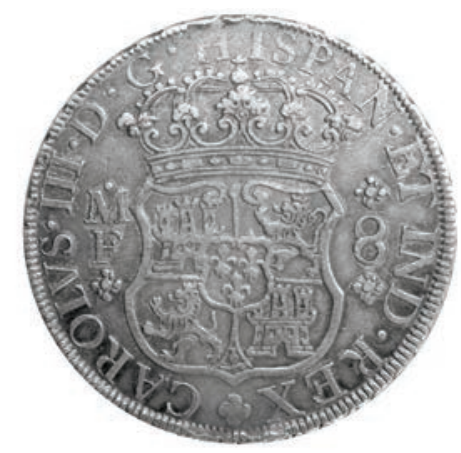

Anverso (A) y reverso (B) de una moneda de plata tipo dos mundos o columnaria. El anverso mues- tra el Viejo y el Nuevo mundo, las columnas de Hércules, la leyenda Vtraque Vnum y la fecha de emisión (1769). En el reveso se indica el valor en reales (8) y el escudo de armas. En la orla, Carlos III por la gracia (G) de Dios (D) de España (HISPAN) e Indias (IND) rey. Los símbolos son de la Casa de Moneda de México. 
Por lo tanto, esos símbolos proclamaban el poderío global de España. La mejor alusión a la independencia de Guatemala fue la separación de los dos hemisferios, hecha ésta por una figura masculina (el "genio de la Libertad con alas y vestido a lo americano", según documento guatemalteco del 29 de noviembre de 1821 citado por Lines, 1971). La cabeza del genio lleva una corona de laurel europeo (Laurus nobilis) símbolo de mérito y sostiene en su mano izquierda una rama de olivo (Olea europaea) símbolo de surgimiento desde los tiempos bíblicos de Noé. La mano derecha sostiene una cornucopia o cuerno de la abundancia colocado sobre el hemisferio que representa al Nuevo Mundo, que extiende su brazo amistoso al Viejo Mundo.

\section{Las medallas de proclamación de 1822}

La noticia de la independencia de Guatemala llegó a Cartago el 13 de octubre de 1821 y el 29 de ese mes Costa Rica se declaró independiente del gobierno español (A.N.C.R., Municipal 841). Esta fecha ha sido propuesta como la pertinente para celebrar la independencia de Costa Rica (ver Monge Pereira, 2012). El 1 de diciembre de 1821 se aprobó el Pacto de Concordia considerado como la primera Constitución de Costa Rica y el 13 de enero de 1822 entró en funciones la primera Junta Superior Gubernativa.

La llegada de la noticia de la independencia de Guatemala no fue bien vista por todos, especialmente, por aquellos que durante el régimen colonial tuvieron beneficios y privilegios. Por tal motivo, la idea de continuar con un sistema tipo colonial fue apoyada por algunos sectores en Cartago y Heredia. El movimiento monárquico más cercano era el liderado por Agustín de Iturbide en México.

En México, el 18 de mayo de 1822 se optó por una monarquía encabezada por Iturbide, quien fue coronado emperador el 21 de junio. Las principales cecas mexicanas emitieron monedas y medallas con la efigie de Agustín I ${ }^{\circ}$., como la ilustrada en la Figura 4A. En la región de Mesoamérica las ciudades afines al imperio de Iturbide decidieron en 1822 acuñar medallas de proclamación en su honor. Se conocen cuatro tipos de medallas emitidas a nombre de Chiapas, Quezaltenango, Guatemala, y León, todas con fecha 1822 y acuñadas con el diámetro y peso de las monedas de un real en circulación en esa época. Según Buttrey (1967) cabe la posibilidad de que las cuatro piezas fueran acuñadas en Guatemala en
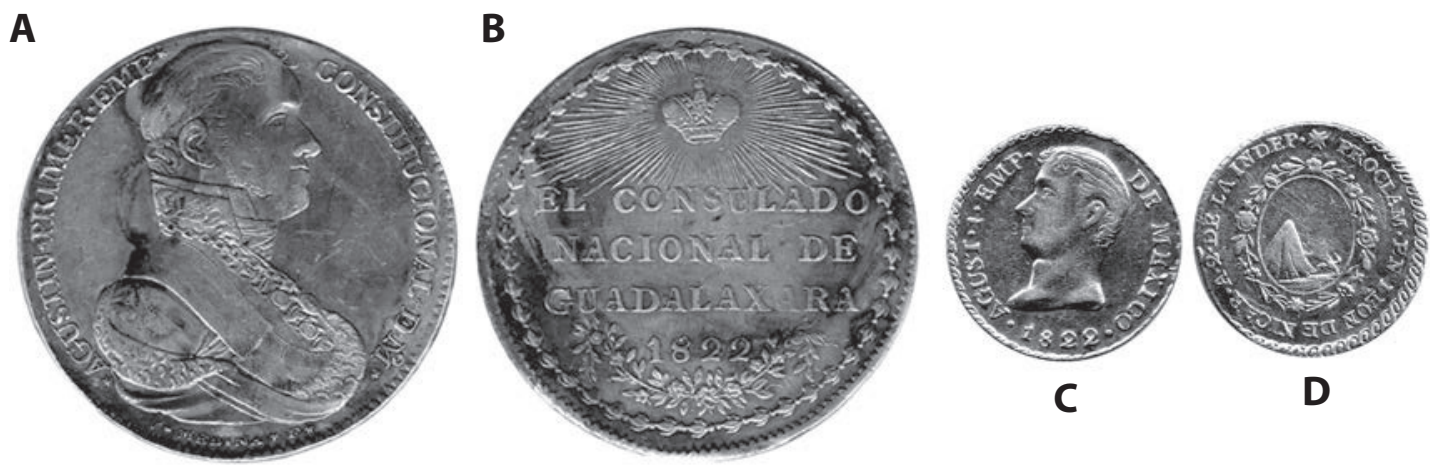

Anverso (A) y reverso (B) de la medalla de proclamación de Agustín I $^{\circ}$ como emperador constitucional de México emitida por el consulado de Guadalajara, México, 1822. Peso 24.4 g. Diámetro $39 \mathrm{~mm}$. Anverso (C) y reverso (D) de la medalla de proclamación de Agustín Io como emperador de México y emitida por la ciudad de León en 1822. Peso 3.1 gramos. Diámetro $20.6 \mathrm{~mm}$. Plata 903/1000. Estas medallas eran aceptadas como monedas de un real. El reverso tiene en la orla la leyenda: Proclamado en León de Nicaragua año 2 de la Independencia y el escudo de la ciudad de León, rodeado de una corona invertida de hojas, flores y frutos similares al mirto (símbolo de paz). 
diciembre de 1822 y como una forma de reafirmar el decreto emitido por Iturbide que dividió la región en tres comandancias generales (Chiapas, Guatemala y León). En la Figura 4B se incluye un ejemplar de la medalla correspondiente a la ciudad de León, que en la actualidad es la pieza más escasa de las cuatro. Nótese que esa medalla, así como la de la independencia de Guatemala (Figura 2) tienen grabada una cruz (tipo Malta) por razones que no conocemos. También la de Quezaltenango tiene ese símbolo.

\section{¿Una medalla a Iturbide hecha en Cartago?}

La medalla de proclamación de Iturbide correspondiente a la ciudad de León es pertinente en el estudio de la numismática costarricense, pues a mediados de 1822 el gobierno de Iturbide sometió a Costa Rica a la jurisdicción de León y se ordenó prestar juramento de fidelidad al emperador, lo que nunca fue cumplido. Es posible entonces que en la capital de Costa Rica (Cartago) se iniciaran preparativos para la jura y para la acuñación de una medalla alusiva. Es interesante en este contexto un documento fechado en la ciudad de Cartago el $1^{\circ}$ de octubre de 1822 en el que Manuel García Escalante (Tesorero General de Costa Rica) envía al presidente de la Junta Superior Gubernativa "una medalla grabada con un rostro en que se manifiesta lo adelantado del cuño que V.E. puso a mi cuidado" (Jara 2007, p. 105). Este prototipo de medalla fue acuñado con la intención de hacer luego una emisión de piezas en oro para envío a México.

No han aparecido documentos que permitan relacionar a las medallas acuñadas en Guatemala en diciembre de 1822 con la pionera de Cartago acuñada en octubre, aunque han sobrevivido medallas de las otras cuatro ciudades, no se conoce el prototipo cartaginés ni las de oro, si las hubo. Sin embargo, ese prototipo posiblemente tendría el mismo formato que el de las otras cuatro medallas; esto es, el busto de Agustín I ${ }^{0}$ en una cara y el escudo de Cartago (otorgado por Felipe II en 1565) en la otra.

Según lo mencionan Vargas Zamora y Chacón Hidalgo (2016), Iturbide fue forzado a abdicar el 19 de marzo de 1823. La lentitud de las comunicaciones hizo que al mes siguiente en Costa Rica se diera la primera guerra civil por un motivo ya inexistente. El choque entre imperialistas a favor de Iturbide (Cartago y Heredia) y republicanos (Alajuela y San José) en la batalla del 5 de abril de 1823 en Ochomogo, hizo de San José la nueva capital ante la victoria de los republicanos liderados por don Gregorio José Ramírez. A don Gregorio se le rendiría homenaje 158 años después (1981) con las emisiones de monedas conmemorativas en oro (5.000 colones) y en plata (300 colones). El retrato de don Gregorio ya había sido incluido en los billetes de 20 colones, serie F, del Banco Nacional de Costa Rica emitidos entre 1945 y 1948 y como serie provisional del Banco Central entre 1950 y 1951.

\section{¿Por qué medallas de proclamación?}

Durante más de trescientos años y especialmente después de 1772, cuando dio inicio el grabado de la efigie del rey en las monedas, éstas reforzaron el dominio de España sobre América. En España era costumbre que con la coronación de cada rey las autoridades civiles, militares y eclesiásticas le juraran fidelidad y se proclamaba el nuevo monarca. Como parte de este acto, el cual se realizaba en la plaza principal con la participación del pueblo, se lanzaban monedas y medallas conmemorativas a la jura y proclama, las cuales mostraban en una de sus caras la efigie del rey para darlo a conocer. Esta costumbre se trasladó al Nuevo Mundo y, al igual que en España, era acompañada de fiestas populares. Los primeros festejos de este tipo se realizaron en Lima el 25 de julio de 1557, con motivo del ascenso de Felipe II (1556-1598) al trono. El arzobispo lanzó monedas de dos reales a los reunidos en la plaza principal (Chacón Hidalgo, 2012).

En Costa Rica también se realizaron actos de jura y proclama de los reyes de España, acompañados de festividades acatando el protocolo y en los que se lanzaron monedas al pueblo, como en 1725 (Luis Iº), en 1791 (Carlos IV $^{\circ}$ ) y en 1809 (Fernando VII'). Según Fernández Guardia (2006) el 16 de noviembre de 1724 llegaron a Cartago noticias sobre el ascenso de Luis $\mathrm{I}^{\mathrm{o}}$ al trono español. Sin embargo Las celebraciones de proclama fueron pospuestas para tomar ventaja del clima de la época seca y duraron 10 días a partir del 20 de enero de 1725. El 21 se lanzaron monedas de un real al público reunido en 
la plaza principal de Cartago. El noveno día cerró con la representación de una batalla naval entre dos barcos montados sobre ruedas y construidos a propósito. Los festejos concluyeron con una representación teatral en la casa del gobernador don Diego de la Haya. Varios meses después llegaría a Costa Rica la noticia de que el rey Luis $I^{\circ}$ había muerto de viruela el 31 de agosto de 1724 a los 17 años de edad.

Para la celebración del ascenso de Carlos IV en 1791 se destinaron 50 pesos (equivalentes a 400 monedas de 1 real) para regalarlos en la plaza de Cartago (Chacón Hidalgo, 2012).

\section{Las primeras monedas de la Costa Rica independiente}

Ahora bien, es interesante la posible existencia en 1822 de artesanos en metalurgia (ensayador y grabador) y de algunas facilidades para la acuñación de moneda en Cartago, pues no fue sino hasta después de 1824, cuando Costa Rica se incorporó como Estado al sistema federal, que se empezó a acuñar moneda en el país (emisión provisional de 1825, Los Horcones, Alajuela) y luego en forma discontinua por la Casa de Moneda en San José fundada en 1828. Además, se debe precisar que las emisiones de monedas se caracterizaron por incluir en los reversos algunos símbolos asociados a las prioridades o virtudes gubernamentales, como la palmera datilera del Viejo Mundo (Phoenix dactylifera, símbolo de rectitud y victoria) en la emisión provisional de 1825 y el árbol de ceiba centroamericano (Ceiba pentandra, símbolo de libertad) en las emisiones en oro a partir de 1828 y en las de plata a partir de 1831. En el anverso se incluyó el escudo de armas de la Federación (Figura 5A).

En 1838 el Jefe de Estado don Braulio Carrillo separó a Costa Rica de la Federación Centroamericana convirtiéndola en un estado soberano (Estado de Costa Rica) representado en el anverso de las nuevas monedas de oro y plata (1842) por una estrella radiante (esto es, emite luz propia - símbolo de soberanía) de seis rombos y seis puntas (no sólida y de ocho puntas como en interpretaciones posteriores) y en la base una media corona formada por una rama de mirto (Myrtus communis) símbolo de paz y una palma de Phoenix dactylifera, mencionada antes. En el reverso fue grabado (Figura 5B) una planta joven de tabaco (Nicotiana tabacum) cuyo cultivo era la base de la economía antes del auge del café (Vargas Zamora y Murillo Rivera, 2013).

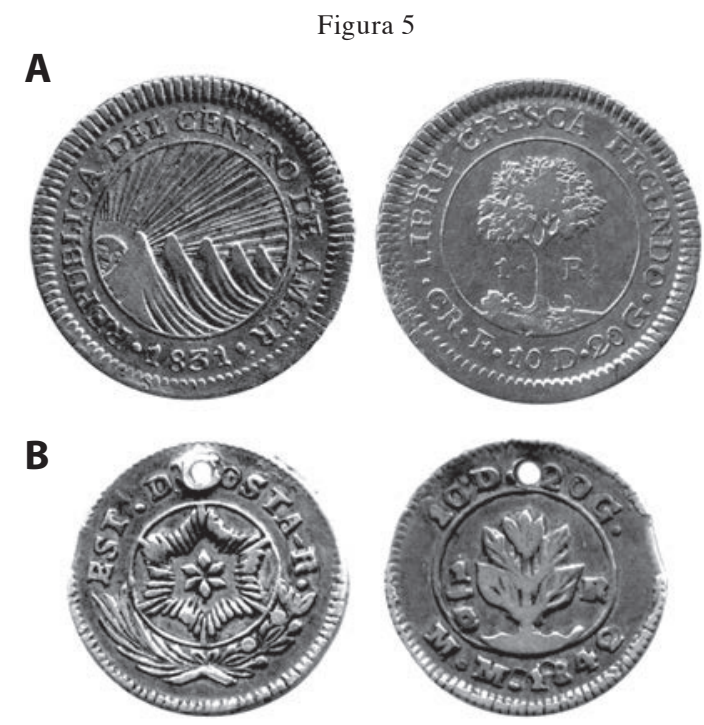

Anversos y reversos de: (A, B) Moneda de 1 real (1 R), Costa Rica (CR), 1831, con el árbol de ceiba (Ceiba pentandra) símbolo de libertad y de la Federación Centroamericana cuyos estados miembros están representados por las montañas. F (Félix Mora, ensayador). Peso 3.38 gramos. Diámetro 20 mm. Plata 903/1000 (10D.20G). B. Moneda de medio real (1/2 R), 1842, con el Escudo del Estado de Costa Rica (estrella radiante de seis puntas), palma y rama de mirto en su base. Reverso con una planta de tabaco (Nicotiana tabacum). M. M. (Miguel Mora, ensayador). Peso 1.5 gramos. Diámetro 18 mm. Plata 903/1000. 
En 1842, Carrillo fue derrocado por el general hondureño Francisco Morazán quien tenía el objetivo de restablecer la Federación. El 20 de abril de ese año Morazán restablece el uso de la moneda federal, así como los antiguos símbolos. Según lo indican Jovel y Chacón:

Es evidente que la intención de Morazán era eliminar todas aquellos símbolos que representaran la anterior situación de Costa Rica como estado independiente desligado de la Federación, incluyendo la moneda, elemento de uso bastante extendido entre la población, que servía como vehículo para transmitir y legitimar ideas políticas y cuyos grabados contenían el escudo de estrella radiante, que indicaba la existencia de un estado libre e independiente, sin ligamen a ningún otro (2014. p 107):

\section{La proclamación de las constituciones de 1844 y 1847}

Morazán fue fusilado en San José ese mismo año y la dirección del gobierno fue asumida de manera provisional por don José María Alfaro. No obstante que desde 1838 Costa Rica declaró su soberanía, la acuñación de monedas con símbolos federales como la ceiba se reinicia en el país en 1843 ( $1 / 2$ y 1 escudo de oro, $1 / 2$ real de plata) por falta de troqueles grabados con los símbolos del Estado de Costa Rica. En los siguientes años se hicieron emisiones en oro y plata, con símbolos federales, hasta las últimas (de 1 y 2 escudos) y fechadas 1850 (Jovel y Chacón, 2014).

En 1843 se eligió una Asamblea Constituyente que empezó a redactar la nueva Constitución, que fue emitida en 1844. Esta fue presentada al Poder Ejecutivo el 10 de abril de dicho año y fue jurada al día siguiente. En las ciudades principales se realizaron festejos para celebrar la nueva Constitución. Por ejemplo, la edición No49 del Mentor Costarricense (semanario impreso en San José y cuyo precio era de tres reales mensuales), del Sábado 11 de mayo de 1844, relata en la página 161 (Anónimo, 1978) las celebraciones en la ciudad de Heredia el día Domingo anterior, así:

Desde la aurora la artillería, la infantería, la banda militar i los fuegos artificiales anunciaron el respeto que es debido a los principios: un paseo triunfal con la Carta en manos de graciosas jóvenes ricamente vestidas, la formación de las tropas, las danzas rurales i las corridas de toros ofrecieron al numeroso concurso, animado de la más estrecha confraternidad y armonía, pruebas inequívocas de satisfacción i placer con que los virtuosos Heredianos han recibido la emisión i juramento de la nueva lei fundamental. Terminaron las diversiones con un baile suntuoso, por la asistencia que a porfía prestó lo más selecto de la población, por la hermosura con que lo adornó el bello sexo, por la comodidad i vista de la sala destinada al efecto, i por el orden que a la par del regocijo i del contento reinó en todo él. Una opípara mesa de colación de distintas especies, acompañada de esquisitos licores brindó a los concurrentes agradables intervalos i una ligera refocilación en la vigilia que se extendió hasta las cuatro de la mañana del Lunes.

Esas celebraciones tenían mucha similitud con las que en tiempos coloniales se hicieron para proclamar al nuevo monarca, según las hemos descrito. La edición del 25 de mayo de 1844 del Mentor Costarricense menciona que los gastos de las fiestas celebradas en las ciudades principales en honor a la Constitución de 1844 alcanzaron un total estimado de 1.500 pesos, suma importante para la época. Las festividades permitían que personas residentes en los centros de poblaciones, así como otros que vivían alejados de estos, tuviesen la oportunidad de reunirse e intercambiar información y productos, además de disfrutar de las raras ocasiones en que se hacían festividades de tal magnitud auspiciadas por el gobierno.

En la edición del Mentor Costarricense del 11 de mayo de 1844 aparece en la página 163 un comunicado sobre la escasez de la moneda de plata:

Es bien sensible el perjuicio que experimenta el público de poco tiempo acá, por la falta de moneda de plata, tan necesaria para la prontitud de los cambios, i solo se ve correr la moneda de oro con sumo trabajo. Los contratos se entorpecen por esta causa, por que á más de repugnarse el oro en pago de jornales, fletes i compra de víveres $\&^{\mathrm{a}}$, se nota dificultad en hallar medias onzas, cuartas i escudos. 
Para solucionar parcialmente el problema de la escasez de circulante de plata la Casa de Moneda habilitó (mediante resellos) el año siguiente las pesetas españolas por valor de dos reales. En 1846 se hizo lo mismo con las monedas macuquinas coloniales de uno, dos, cuatro y ocho reales. En 1850 fueron resellados los peniques y chelines ingleses que circularon por valor de uno y dos reales, respectivamente. Dentro de este contexto, la emisión en 1947 de una moneda conmemorativa (pero aceptable en las operaciones comerciales) fue, posiblemente, muy bien recibida por el pueblo, especialmente, si muchas de las monedas les fueron obsequiadas, según lo explicamos más adelante.

\section{La primera moneda conmemorativa de Costa Rica}

Don Francisco María Oreamuno fue electo Jefe de Estado en 1844, pero después de un mes abandonó el poder por decisión propia y para sustituirlo fue nombrado don José Rafael Gallegos. En 1846 Gallegos fue a su vez separado del poder por un golpe de estado y don José María Alfaro fue declarado como Jefe Provisorio, por segunda vez en la década. Posteriormente, se convocó a una nueva Asamblea Constituyente, la cual elaboró la nueva Constitución que entró en vigencia en 1847.

Para celebrar las reformas de 1846 (el golpe de Estado a Gallegos, ocurrido el 7 de junio) y la nueva Constitución de 1847, la Casa de Moneda acuñó la primera moneda conmemorativa de Costa Rica, con valor de un real (Figura 6). Nótese que tanto las medallas de proclamación mencionadas antes, como en este caso la moneda conmemorativa cumplen la función de proclamar nuevas formas de gobierno.

Figura 6

A

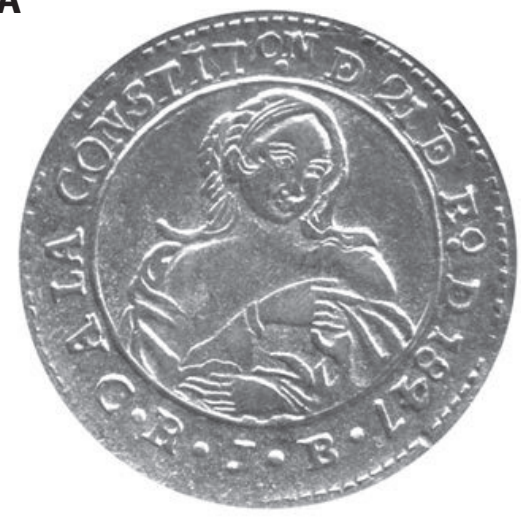

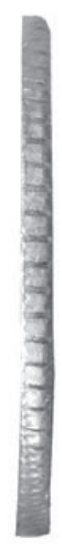

B

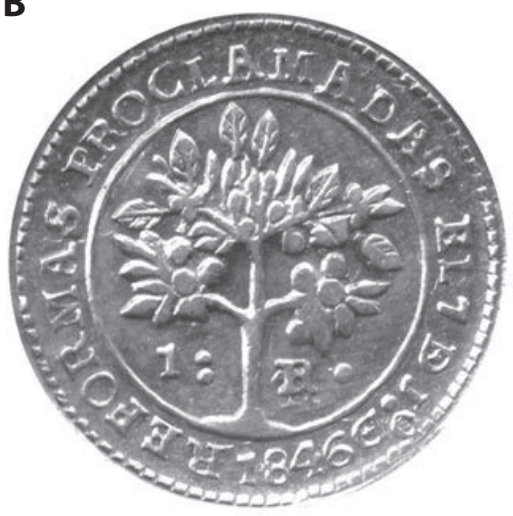

Anverso (A), canto con cordoncillo estriado, y reverso (B) de la primera moneda conmemorativa emitida en Costa Rica. En las orlas: A la Constitución de 21 de Enero de 1847 y Reformas Proclamadas el 7 de Junio de 1846. En el anverso se incluyó un arbusto de café (Coffea arabica) cultivo principal. Un real (1 R), J. B. (Juan Barth, ensayador). Figura femenina que representa a una joven indígena. Peso 2.9 gramos. Diámetro 20 mm. Plata 903/1000. 
El decreto para la emisión de esas monedas fue emitido el 10 de febrero de 1847 y en su artículo 2 dice según Murillo:

Esta consistirá en reales acuñados especialmente para tal objeto con el peso i lei correspondiente i cuyo tipo sea por el anverso un árbol de café ocupando el centro i la circunferencia una leyenda que diga "Reformas Proclamadas el 7 de junio de 1846" i por el reverso el rostro de una joven india, en el centro, i en la orla ésta inscripción "Costa Rica a la Constitución de 21 de enero de 1847 (2004,p. 64)

\section{La moneda botada al pueblo}

El Gobierno destinó 2.200 de las monedas de un real de 1847 (equivalentes a 275 pesos, pues 1 Peso $=8$ reales) para ser repartidas (botadas) entre el pueblo, por medio de los sacerdotes, en las cabeceras de los cinco departamentos del Estado el día 7 de marzo de 1847 (día de la jura de la Constitución), de la siguiente forma: San José, 800 monedas; Cartago, Heredia y Alajuela (400 c/u) y 200 para Guanacaste. Las 2.200 piezas regaladas al pueblo probablemente no fueron el total de la emisión, pues en el "Cuadro de las monedas acuñadas en la República desde el año 1829 a 1882, según libros de la Casa de Moneda" (elaborado por Manuel Quirós en 1883, e ilustrado en Murillo, 2004), se anotó para el año 1847 un total de 708 pesos y 12 reales como costo de las monedas de un real. Este monto podría corresponder aproximadamente a 5.564 piezas. Según Murillo aunque esas 2.200 monedas fueron obsequiadas al pueblo, el artículo $3^{\circ}$ del decreto especificaba que estas eran de curso legal y era delito el no recibirlas en operaciones de cambio. El lanzamiento de monedas al pueblo por parte de las autoridades eclesiásticas era símbolo de prosperidad, la cual proviene de Dios por medio del gobernante. Tal vez este acto simbólico esté asociado a la expresión "botar la plata" que ha sobrevivido hasta la actualidad para indicar el despilfarro de dinero. Otro dato interesante es que esas monedas fueron acuñadas siguiendo el formato tipo medalla; es decir, las caras opuestas de la pieza quedan en la misma posición al girarla sobre el eje vertical. En la acuñación tipo moneda, una de las caras queda en posición invertida.

\section{Las festividades asociadas}

Para celebrar la proclama de la Constitución de 1847 se realizaron festejos en las cuatros ciudades principales de Costa Rica. La crónica de los celebrados en San José relata, según Chacón Hidalgo:

\footnotetext{
La Constitución fue llevada con la mayor pompa y solemnidad en un carro ricamente adornado, en que aparecía una joven graciosa, vestida a la india, desde el salón de sesiones del Cuerpo Legislativo hasta el tablado que en la plaza se había preparado al intento. El Doctor Castro, Vice -Jefe recibió de la joven el Código de los derechos del Pueblo... El señor Cura botó al pueblo una cantidad de dinero acuñado al efecto con emblemas demostrativos de las reformas proclamadas. (2000, p. 63).
}

Según Chacón Hidalgo (2000) el fin de toda esta celebración fue dar a conocer y legitimar la nueva Carta Magna, que luego sirvió de base para que el Dr. Castro Madriz emitiera, en 1848, el decreto de fundación de la República de Costa Rica. Nuevamente, las monedas constituyeron un medio para proclamar el nuevo orden administrativo Con base en los antecedentes presentados es evidente que las juras de las constituciones de 1844 y 1847 contenían actividades comunes desde tiempos coloniales: En el desfile de las principales autoridades el estandarte español es sustituido por la Constitución. En la Plaza Principal (hoy Parque Central de San José), la Constitución se entregó a la persona designada que realizó la jura y lectura de la misma, al igual que en tiempos coloniales se le entregaba la bandera española y las cartas del rey que serían leídas en voz alta por su representante. Luego las autoridades eclesiásticas son las encargadas de lanzar al pueblo la moneda que conmemora el acto. Finalmente, se 
llevaron a cabo más desfiles y fiestas para las autoridades civiles, militares y eclesiásticas y para el pueblo (comidas, bailes, fuegos artificiales, mascaradas, entre otros elementos).

Es importante recalcar que desde tiempos antiguos las monedas fueron mensajeros importantes, pues los medios de comunicación impresos (como el semanario Mentor Costarricense a mediados del siglo XIX) eran muy limitados y solo una parte de la población tenía acceso a ellos y aun menos sabían leer y escribir. La moneda se convirtió en el objeto de uso más generalizado para divulgar los ideales de los grupos políticos que ejercían el poder, debido a su utilización cotidiana como medio para la compra de bienes y servicios, sobre todo en momentos de cambio en que se implementaron nuevas formas de organización política del Estado.

\section{La figura de la joven indígena la moneda de 1847}

La figura de una nativa del Nuevo Mundo era preferida en el imperio español para representarlo, como contraste a la figura femenina (Hispania) con que se identificaba a la región de España en monedas desde tiempos del imperio romano. Además, existía la intención de relacionar los orígenes de Costa Rica con un pasado lejano y como un territorio independiente desde 1821, dos argumentos importantes para el establecimiento posterior de la República en 1848.

El rostro de una joven indígena no es el primero grabado en monedas del Nuevo Mundo, pues en 1819-1820 nuestros vecinos de Nueva Granada incluyeron la efigie de la esposa del cacique de Cundinamarca (Temprano, 1993) en sus monedas (Figura 7A) en directa oposición a la imagen del rey Fernando VII ${ }^{\circ}$ (Figura 7B). En las piezas de plata de Nueva Granada destaca además la leyenda desafiante "Libertad Americana" y a la moneda se le conoció como la "insurgente de las Américas". Un total de 571 piezas de ocho reales (Ocho Reales $=1$ Peso) fueron introducidos en Costa Rica por el sacerdote Gabriel Padilla y evaluadas en Cartago por dos plateros (tal vez los mismos involucrados luego en la acuñación de la medalla a Iturbide mencionada antes) y nombrados ensayadores del Estado.

A

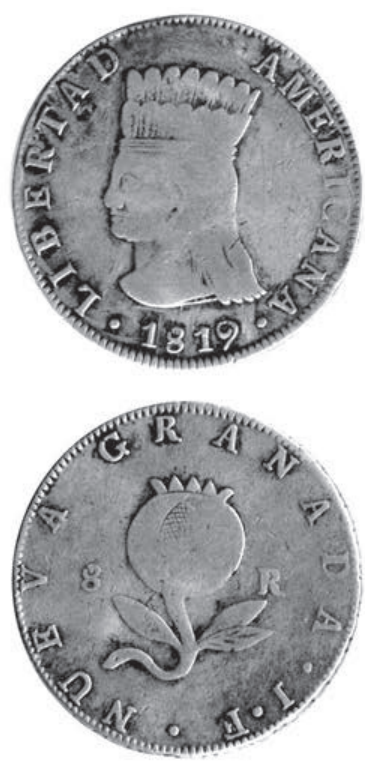

Figura 7

\section{B}

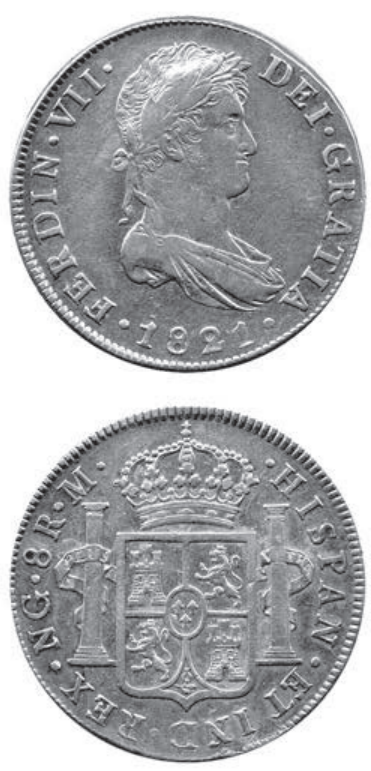

Anversos y reversos de: A. Moneda de ocho reales (1 Peso), Libertad Americana, 1819, Nueva Granada. Busto de la esposa del cacique de Cundinamarca. Fruta de la granada europea (Punica granatum). Peso 24.8 gramos. Diámetro $38 \mathrm{~mm}$. Plata 666/1000. B. Moneda de ocho reales (8R), Nueva Guatemala (NG) 1821. Busto del rey Fernando VII. Escudo de armas de España. Peso 27 gramos. Diámetro 36 mm. Plata 896/1000. 
De acuerdo con Murillo (2004) mediante decreto del 19 de julio de 1822 se autorizó la circulación de la moneda insurgente (sometida previa evaluación del contenido de plata y del peso de las monedas) por valores de ocho, siete y seis reales (indicados mediante resellos) o inhabilitada si era de calidad inferior. Creemos que posiblemente ocurrió lo último con las insurgentes, pues esas monedas tienen un contenido menor de plata (666/1000) que las coloniales (generalmente 903/1000). El peso en gramos es también menor (el ejemplar ilustrado pesa $24.8 \mathrm{~g}$ ) que en las coloniales $(27.0 \mathrm{~g})$ y en la actualidad no se conoce ningún ejemplar resellado.

\section{El sobrenombre "mariquita"}

Las monedas conmemorativas de 1847, así como las emisiones similares de 1849 y 1850 , fueron conocidas como mariquitas. No obstante, que el reverso de la moneda el decreto indica que es una joven indígena (Figura 6), la imagen grabada contiene elementos que la asemejan a modelos artísticos europeos, de los que mencionaremos dos:

En el primero, la posición de las manos y la forma del rebozo dan la idea de una madre con un niño en brazos, que también podría interpretarse como el nacimiento de la República. El diseño la hace semejante a representaciones renacentistas de la Virgen María, razón por la cual, posiblemente, el pueblo las llamó: 'ariquitas', más aún cuando fueron los curas los encargados de botarlas.

El segundo modelo la relaciona, según Vargas Zamora, con la pintura de Rafael Sanzio (conocida como La Fornarina, de 1516) en la que la forma de sostener la tela entre los dedos índice y cordial de la mano derecha, el tocado del cabello y otros rasgos son similares a los de la imagen en la moneda.

El sobrenombre mariquita también pudo tener su origen en el hecho de que, según Marr (2004), don Manuel José Carazo (Figura 8A) y su esposa doña María Toribia Peralta (Figura 8B) eran dueños de una tienda de variedades en la calle del Carmen en el centro de San José. De ellos dice Marr, quien compró en esa tienda cuatro cajetillas de fósforos por un real en 1852:

Figura 8
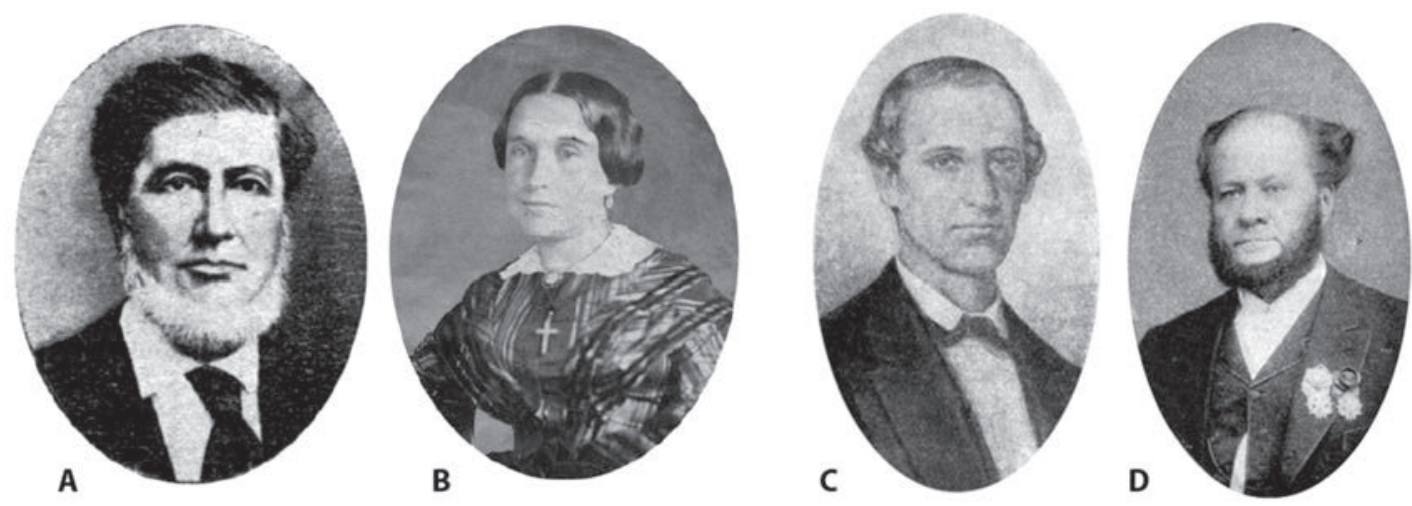

A. Don Manuel José Carazo Bonilla, Ministro de Hacienda. B. Doña María Peralta Echeverría (Mariquita), esposa de Carazo (foto cortesía de doña Elisa Carazo Alfaro, bisnieta de don Manuel). C. Don José María Alfaro Zamora, Jefe Provisorio (1846-1847). D. Dr. José Maria Castro Madriz, primer Presidente (1847-1849) de la Republica de Costa Rica. 
Aquel señor era nada menos que don Manuel José Carazo, ministro de Hacienda y de Guerra de la República de Costa Rica, el hombre más sesudo, hábil, talentoso y, desde el punto de vista centroamericano, el más cortés del todo el país. La señora era su esposa doña Mariquita.

Era la primera vez que la imagen de una joven aparecía grabada en las monedas de Costa Rica y es de suponer que el pueblo, que trataba con doña Mariquita en su tienda, asociara la imagen en la moneda con la esposa del funcionario gubernamental de alto rango, bajo cuya influencia estaba la Casa de Moneda.

\section{Las mariquitas de 1849 y 1850}

Para suceder a don José María Alfaro (Figura 8C) se realizaron elecciones en 1847 en las que resultó electo como Jefe de Estado el Dr. José María Castro (Figura 8D), quien el 30 de agosto de 1848 emitió el decreto que declaró a Costa Rica nación soberana e independiente, con el nombre de República de Costa Rica y el Dr. Castro fue su primer Presidente.

En 1849 se acuñó la moneda (1 real) en la que por primera vez aparece grabada en la orla del anverso la leyenda: 'República de Costa Rica'. En la orla del reverso se grabó: 'América Central', ambas en letras mayúsculas. El diseño fue repetido en una nueva acuñación fechada 1850. Los centros de las mariquitas de un real de 1849 y 1850 (Figura 9 A, B) conservaron las figuras de la joven indígena y el cafeto de la mariquita conmemorativa de 1847 , por lo que también recibieron ese sobrenombre y fueron acuñadas con el formato tipo medalla. A diferencia de las piezas de 1847 que tienen el canto estriado (Figura 6), las de 1849 y 1850 lo presentan al estilo colonial en forma de cadena (Figura 9).

Figura 9

A

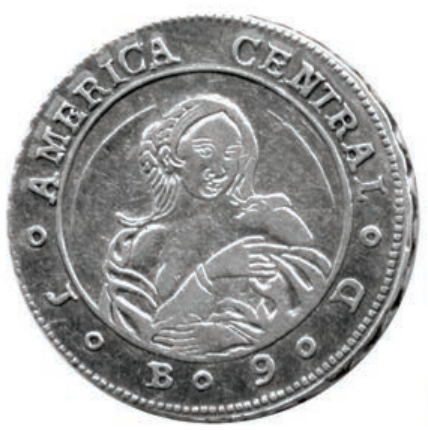

B

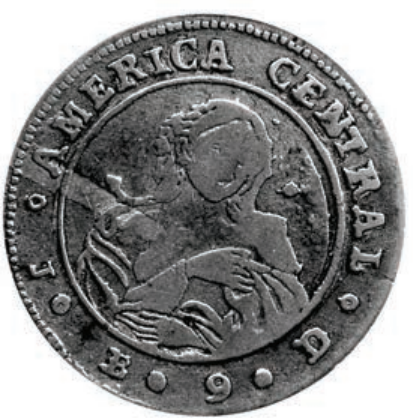

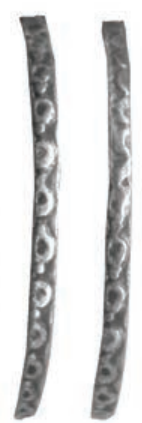
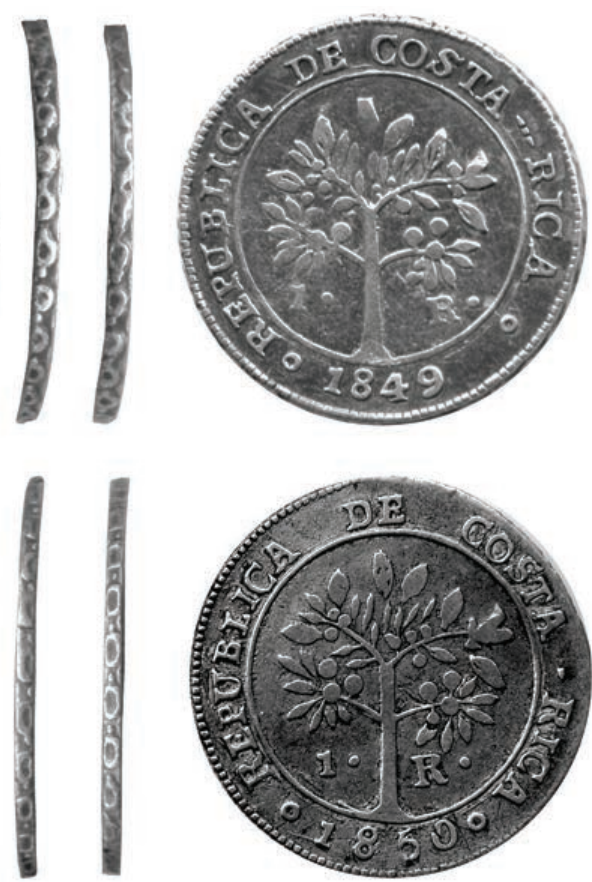

Anversos, reversos y cantos (con cordoncillo colonial encadenado) de: A. Moneda de un real de 1849, plata 750/1000 (9.D.), retroquelada y con restos (semi-círculos) de figuras de la moneda original. B. Moneda de un real de 1850, plata 750/1000, retroquelada, con restos (puntos) de figuras de la moneda original. 
No obstante estas emisiones con nuevos símbolos y los decretos de 1838 y 1848, la falta de troqueles, el auge de la economía cafetalera y la circulación de moneda falsa, hicieron necesario que entre 1843 y 1850 la Casa de Moneda acuñara monedas de oro y de plata con símbolos federales y resellara moneda extranjera para que circulara legalmente en el país, tal como se mencionó antes.

\section{El cafeto}

Las mariquitas son las únicas monedas de Costa Rica (desde 1825 al presente) en las que en el anverso no fue grabado el escudo de armas y en su lugar se incluyó un arbusto de café.

Según lo indica González Flores (1934) el cultivo del café (Coffea arabica) había empezado a tomar auge desde su introducción en el país alrededor de 1808. Don Braulio Carrillo ya había ordenado en 1842 la inclusión de un cafeto en las monedas de oro; sin embargo, por falta de troqueles se grabó una ceiba. El año siguiente la cosecha fue de cerca de 35.000 quintales (1 quintal = 100 libras, 1 libra $=460$ gramos) y la de 1844 aumentó a 50.000. Gracias a las mejoras hechas al camino a Puntarenas para el tránsito de carretas, más de 500 de estos vehículos de madera, tirados por bueyes guiados por boyeros, transportaron al puerto gran parte de la cosecha de 1844. Los boyeros cobraban por el flete a razón de 20 reales por 10 arrobas (esto es, 20 reales por 250 libras $=1$ peso por quintal). El viaje de ida y regreso al puerto demoraba cerca de 10 días (Anónimo, 1978).

El cafeto en las mariquitas (Figuras 6 y 9) representa una planta joven con varios frutos (estos grabados a escala mayor que el resto del arbusto) en cuatro ramas en pares opuestos, como en la naturaleza. En algunas monedas con poco desgaste se observan las nervaduras de las hojas, también grabadas ambas acorde con la realidad botánica. El grabado del cafeto pregona entonces la importancia del principal cultivo de Costa Rica a mediados del siglo XIX.

\section{Las iniciales J.B. y el peso de las monedas}

En las mariquitas aparecen grabadas las iniciales J. B. (Figuras 6 y 9), que corresponden al inmigrante alemán Johann (Juan) Barth quien fungió entre 1847 y 1864 como ensayador-director de la Casa de Moneda; esto es, estaba encargado de certificar que el peso y la ley (contenido de metal precioso) de las monedas fuesen los legales. La mariquita de 1847 tiene grabado 10D.20G (10 Dineros.20 Granos) que corresponde a 903 milésimas de plata pura. En las mariquitas de 1849 y 1850 (Figura 9) la ley está indicada por 9.D. (9 Dineros), que equivalen a 750 milésimas. Volvemos sobre este tema más adelante.

Desde la época colonial y hasta avanzado el siglo XIX las monedas que circularon en Costa Rica estaban regidas por el sistema bi-metálico (oro-plata) español. En este sistema y a partir de 1728, las monedas de ocho escudos (Onza) de oro y las de ocho reales (Peso) de plata debían pesar 27,064 gramos (g) cada una (Sedwick y Sedwick, 2007). Las denominaciones inferiores pesaban la mitad de la siguiente superior; esto es, para las de plata: 13,532 g (4 reales), 6,766 g (2 reales), 3,383 g (1 real), 1,691 g (1/2 real) y $0,846 \mathrm{~g}(1 / 4$ de real). Sin embargo, estos pesos teóricos variaron, generalmente hacia la baja, según las oscilaciones en el precio de los metales preciosos.

En el Cuadro 1A hemos incluido el peso en gramos de 21 mariquitas en buen estado de conservación (siete de cada fecha. Las monedas fueron lavadas con alcohol para remover suciedad y pesadas a temperatura constante). De esta muestra, solamente una moneda (1847) superó los 3,0 g y la de menor peso fue 2,521 g (1850). Esta última difiere del peso teórico en $0,862 \mathrm{~g}(25 \%)$. El promedio de peso (2.685 g) del grupo de monedas de 1850 parece diferir de los otros años. Sin embargo, la comparación gráfica de los pesos (Cuadro 1B) evidencia sus traslapes, lo que indica que las diferencias entre los tres grupos no son estadísticamente significativas (prueba de Kruskal-Wallis). 
Cuadro 1

A. Pesos en gramos $\left(20^{\circ} \mathrm{C}\right.$ - balanza científica), de tres grupos de siete mariquitas (máximo y mínimo) y peso promedio de cada grupo.

\begin{tabular}{ccc}
$\mathbf{1 8 4 7}$ & $\mathbf{1 8 4 9}$ & $\mathbf{1 8 5 0}$ \\
2.875 & 2.888 & 2.698 \\
2.589 & 2.771 & 2.734 \\
2.693 & 2.746 & $\mathbf{2 . 8 0 6}$ \\
$\mathbf{3 . 0 0 1}$ & 2.667 & 2.586 \\
2.825 & $\mathbf{2 . 9 8 6}$ & 2.521 \\
2.925 & 2.733 & 2.670 \\
2.729 & 2.907 & 2.783 \\
\hline Promedio: & & \\
$\mathbf{2 . 8 0 5}$ & $\mathbf{2 . 8 1 4}$ & $\mathbf{2 . 6 8 5}$ \\
\hline
\end{tabular}

B. Comparación gráfica de los pesos para cada año. (Diferencias no significativas, prueba de Kruskal-Wallis Sobre medianas)

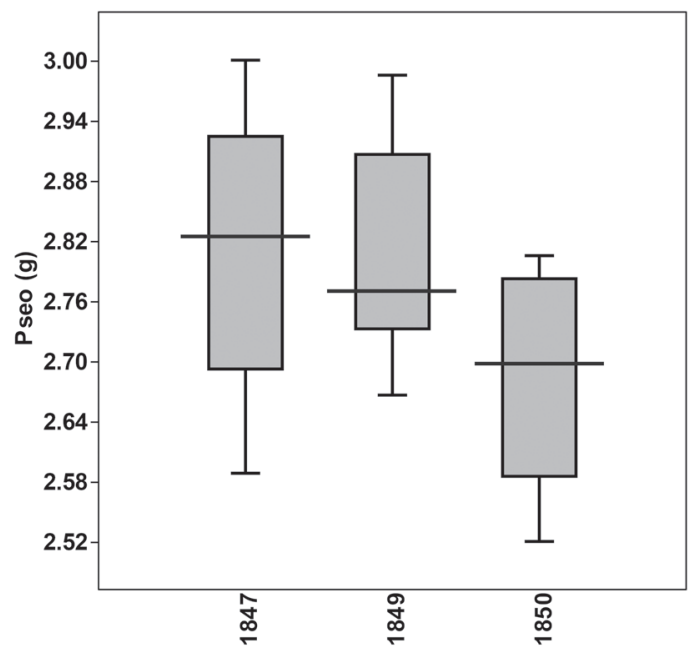

Existen copias (falsificaciones) de estas monedas hechas en un molde e identificables por la porosidad (huellas de burbujas), la marca en el canto por donde se inyectó el metal fundido, la línea de unión de las dos tapas del molde alrededor del canto y el peso menor (alrededor de $2.0 \mathrm{~g}$ ).

\section{Algunos detalles técnicos sobre la fabricación de las mariquitas}

La investigación realizada y el análisis de 21 mariquitas de los tres años de emisión (1847, 1849 y 1850) produjeron algunos datos interesantes, como la existencia de lo que podríamos considerar variedades producto de los procesos de fabricación. En la Figura 10 hemos incluido una docena de ejemplos.

Para las monedas de 1847 existieron probablemente varios juegos de troqueles distintos: uno en el que la R de "real", ubicada al lado izquierdo del cafeto, aparece doble (Figura 10A), producto de un doble golpe de punzón al momento de fabricar el troquel. Otra variedad consiste en un error en la inicial B del apellido del ensayador Juan Barth (J.B.) que está al revés (Figura 10B) y finalmente dos variedades caracterizadas por la diferente puntuación separando las letras C.R y J.B (Figura 10 C, D). 

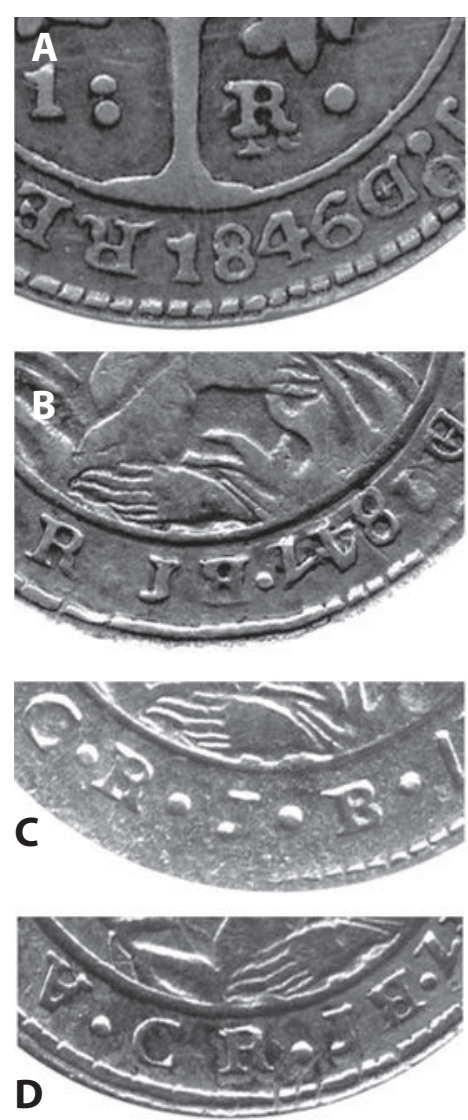
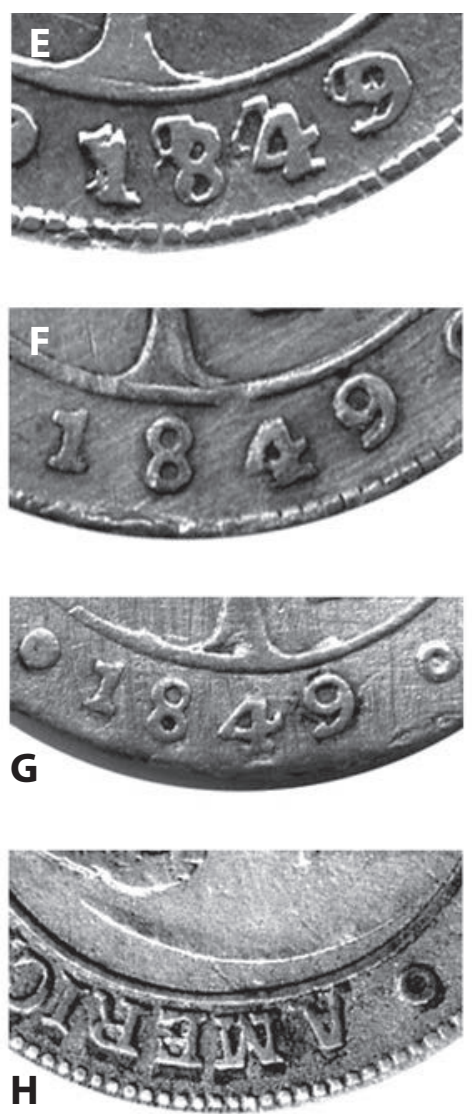
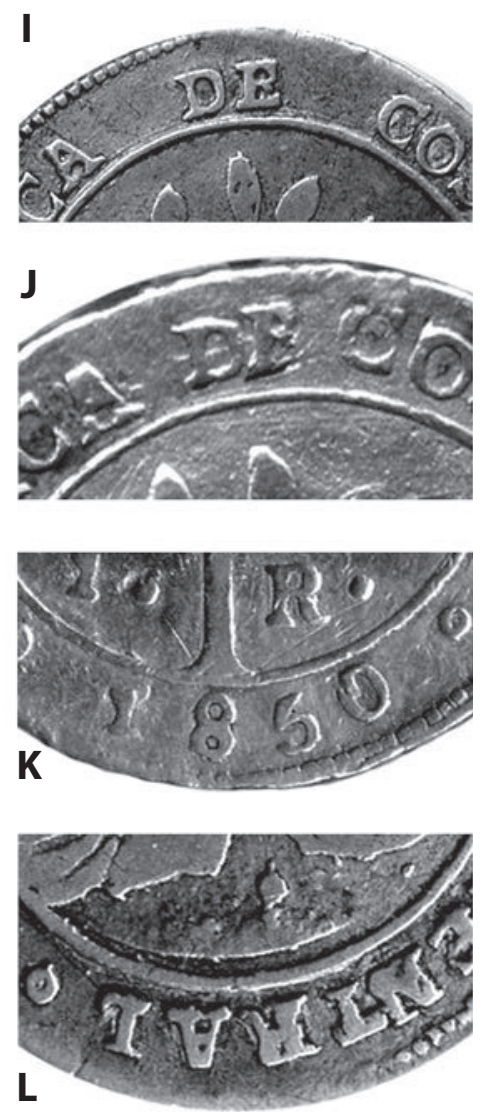

Doce ejemplos de variedades en las mariquitas de 1847 (A-D), 1849 (E-H) y 1850 (I-L): A. Doble golpe del troquel. B. Letra B (Barth) invertida. C. Separación por puntos de las letras C.R. (Costa Rica y J. B. (Juan Barth). D. Otra forma de separación de las letras. E. Base del cafeto sobre el 1 y doble fecha. F. Base sobre el ocho. G. Base sobre el cuatro. H. Restos (linea curva) del grabado de la moneda original Ver Fig. 9A. I. Espacios amplios en la leyenda Republica de Costa Rica. J. Espacios estrechos en la leyenda. K. Base del cafeto sobre el ocho. Comparar con Fig. 9B. L. Restos (línea con engrosamientos) del grabado de la moneda original. Ver Fig. 9B.

Para el año de 1849, y a pesar de lo limitado de la muestra, hemos encontrado al menos tres tipos de troqueles, lo que nos indica una gran producción de mariquitas y un proceso de fabricación artesanal que condujo a diferencias entre una moneda y otra. No se puede determinar la cantidad de mariquitas emitidas en 1849 debido a que los datos proporcionados por el "Cuadro de las monedas acuñadas en la República“" se encuentran mezclados con la emisión de monedas de un real del tipo Federal (con árbol de ceiba) del mismo año. Las variedades se pueden encontrar especialmente en las leyendas, las cuales tienen diferencias de ubicación y dirección en relación con la figura femenina (la joven indígena y distancias distintas entre las palabras e iniciales. Por ejemplo, al menos tres son reconocibles por la posición de la base del cafeto sobre los dígitos 1,8 y 4 de la fecha (Figura 10 E, F, G). También se observa en algunas piezas los restos de figuras grabadas en la moneda original que fue reacuñada (Figura $10 \mathbf{H}$ ). 
En las de 1850 hay variedades distinguibles por la separación de las letras en la orla (Figura 10 I, J), así como una en la que la base del cafeto está entre el 8 y el 5 de la fecha (Figura 9B) y otra en la que la base está sobre el 1 (Figura 10 K). De igual modo que en las de 1849, algunas de 1850 presentan rastros de la moneda original (Figura 10 L). Esta posiblemente fue una emisión muy pequeña, lo cual es reforzado por el hecho de ser 1850 la fecha menos recurrente de la serie de las mariquitas.

Otro detalle importante de destacar sobre las mariquitas es que por la forma de cadena del cordoncillo utilizado en el canto en las de 1849 y 1850 (Figura 9 A,B), se deduce que estas son reacuñaciones, ya que la Casa de Moneda de Costa Rica no tuvo una máquina capaz de producir un cordoncillo de este tipo. Por los restos encontrados en algunas de las monedas estudiadas suponemos que la reacuñación se realizó sobre monedas de un real de la República Federal, ya que los diámetros oscilan entre los 19 y $20 \mathrm{~mm}$ y los pesos se aproximan a los tres gramos, como en las mariquitas. El lado de la joven indígena fue acuñado sobre el lado del escudo federal de volcanes y sol naciente, lo cual se deduce por la forma de los restos de la moneda base.

Los diámetros y pesos de las monedas en los tres años fechados son muy similares, aunque se supone, de acuerdo con la legislación mencionada, que la ley de las monedas varía entre 1847 (903 milésimas) y los años 1849 y 1850 (750). La ley de las monedas de un real de la Federación era 903, al igual que la mariquita de 1847. Suponemos que estas disposiciones no se cumplieron ya que la moneda huésped, posiblemente tenía una ley de 903. Por tanto, es probable que todas las mariquitas tengan una ley cercana a 903 milésimas de plata.

Para aportar datos en apoyo de esta suposición sometimos seis mariquitas (dos de cada año, escogidas al azar del grupo de 21) al análisis de energía dispersiva de rayos X (Energy Dispersive X-Ray) acoplado a un microscopio electrónico de barrido (SEM). El análisis (conocido como SEM-EDX por sus siglas en inglés) ha sido utilizado en el estudio de la composición de diversos tipos de monedas (Dool, 2000). El resultado del análisis (Cuadro 2) indica que ninguna de las seis mariquitas tiene contenido de plata menor de $85 \%$, lo que apoya la reflexión mencionada con anterioridad. Cabe mencionar que la legislación de la época permitía que el valor de 903 milésimas oscilara dentro de límites de tolerancia establecidos. Es interesante que la liga (metales agregados para incrementar la dureza de la moneda) está formada por varios metales y no solamente por cobre, como era costumbre. Estos son resultados para comparar con futuros análisis de otras monedas.

Cuadro 2

Concentraciones (en milésimas) de: plata $(\mathrm{Ag})$, cobre $(\mathrm{Cu})$, plomo $(\mathrm{Pb})$, y otros (hierro + zinc + niquel + oro), en seis mariquitas (a,b) y en 1/16 de Peso (c). Análisis por sensor de Energía Dispersiva de rayos X (EDX), acoplado a microscopio electrónico de barrido (SEM-EDX). CIEMIC, Universidad de Costa Rica.

\begin{tabular}{ccccc}
\hline & \multicolumn{4}{c}{ METALES } \\
MONEDA & $\mathrm{Ag}$ & $\mathrm{Cu}$ & $\mathrm{Pb}$ & Otros \\
\hline $1847 \mathrm{a}$ & 875 & 64.2 & 41.4 & 19.0 \\
$1847 \mathrm{~b}$ & 852 & 56.1 & 69.9 & 22.0 \\
$1849 \mathrm{a}$ & 887 & 46.3 & 49.9 & 16.4 \\
$1849 \mathrm{~b}$ & 894 & 40.0 & 47.6 & 17.8 \\
$1850 \mathrm{a}$ & 888 & 18.4 & 66.9 & 26.4 \\
$1850 \mathrm{~b}$ & 903 & 26.8 & 47.9 & 21.9 \\
$1850 \mathrm{c}$ & 913 & 11.0 & 48.7 & 26.3 \\
\hline
\end{tabular}

Valores máximos (\%): Plata 91.3, Cu 6.4\%, Pb (7.0), Otros 2.6. No hay restos de estaño (Sn). 
Las mariquitas de un real fueron sustituidas a mediados del siglo XIX por las de un octavo de Peso con el grabado del árbol de encina. Según Gurdián Montealegre (1996) estas nuevas monedas tienen un peso teórico de $2,951 \mathrm{~g}$.

\section{La fundación de la República y sus símbolos}

Tal como lo mencionamos antes, en 1848 el Dr. Castro Madriz emitió el decreto por el cual Costa Rica adoptó la forma de gobierno republicana, la que fue pregonada por primera vez por las mariquitas de 1849 y 1850 . Sin embargo, el decreto también especificaba las características de las nuevas monedas de plata y de oro (Figura 11 A, B) que serían acuñadas bajo el nuevo gobierno y de las que hemos escrito en extenso anteriormente (ver Vargas Zamora, 2011). No obstante, cabe resumir que a mediados del siglo XIX el auge del cultivo del café y la necesidad de fortalecer su exportación especialmente a mercados europeos, así como la política gubernamental orientada a estimular la inmigración europea, hizo que las monedas reflejaran en sus anversos esas prioridades: en las de plata se grabó una encina o roble, posiblemente de la especie mesoamericana, Quercus salicifolia. que pregonaba ante el usuario nacional o extranjero la hospitalidad y la fortaleza del país emisor. El género Quercus incluye árboles comunes tanto en Europa como en América (Vargas Zamora, 2014).
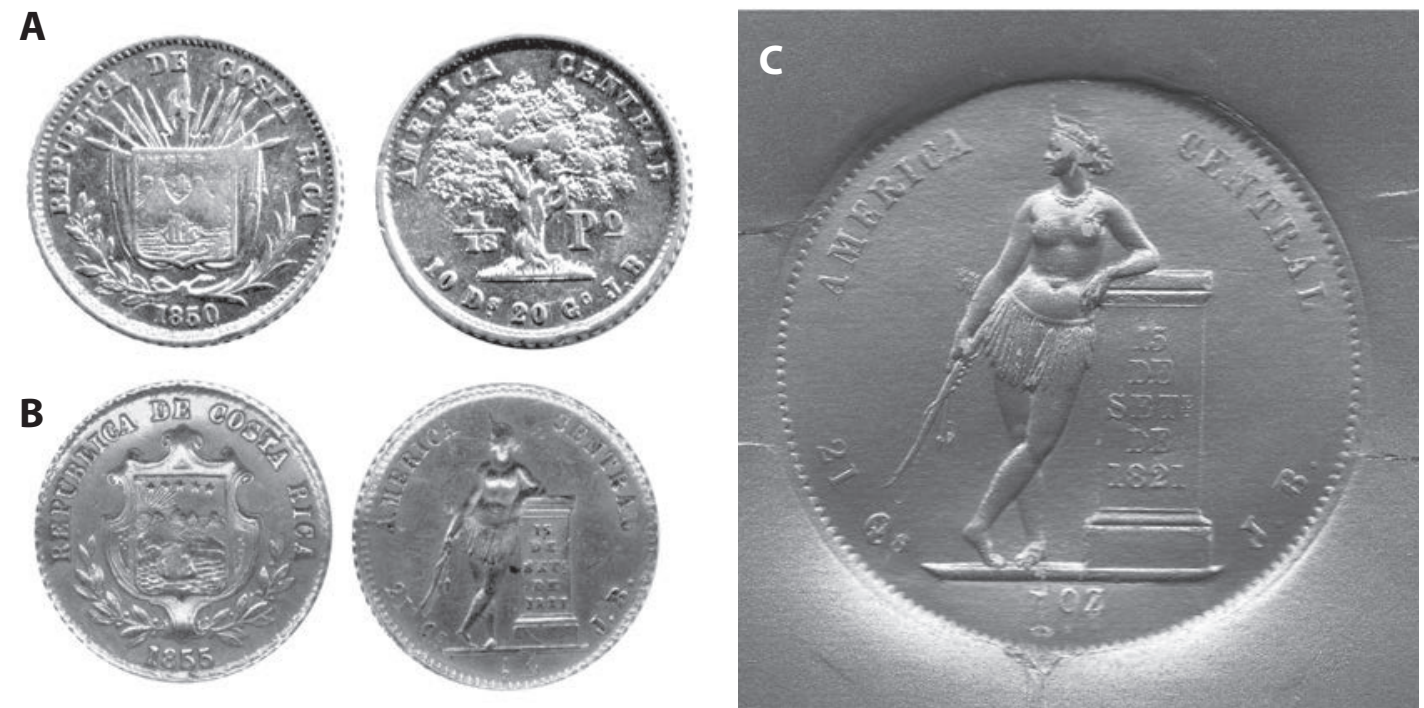

Dos ejemplos de las monedas de la República de Costa Rica según decreto de 1848. Anversos y reversos de: A. Moneda de plata, 1/16 de Peso, 1850, con el árbol de encina (Quercus salicifo- lia ?) y Escudo de Armas, con armas. Peso 1.4 gramos. Diámetro $14 \mathrm{~mm}$. Plata 903/1000. B. Moneda de oro, medio Escudo (1/2 E = 1 Peso), 1855, con la india parada vestida con faldilla y portando flechas (similar a la de la Fig. 2) y Escudo de Armas, sin armas. Peso 1.7 gramos. Diámetro $14 \mathrm{~mm}$. Oro 21 Q. (875/1000). C. Prueba en cartón del troquel de la moneda de una onza ( $1^{\mathrm{OZ}}=8$ Escudos, no acuñada). 
Según Vargas Zamora (2011) los símbolos en las nuevas monedas republicanas de plata (Figura 11 A) pregonaban un mensaje claro a los usuarios: Costa Rica, república joven (el sol naciente), con cinco departamentos (las estrellas), fuerte (las armas), tierra de volcanes entre dos mares, abierta al comercio (los veleros), crece victoriosa, con rectitud y mérito (la palma), pacífica (el mirto) y hospitalaria (la encina).

\section{La figura de otra joven indígena en las monedas de la República}

En las elegantes monedas de oro de la República de Costa Rica se grabó una figura femenina de pie, conocida a mediados del siglo XIX como la india parada, cuyo aspecto, flechas y corona la asemejan a las diosas de la mitología, como Diana. Estas monedas fueron acuñadas con valores de medio (equivalente a un Peso), uno, dos (una cuarta) y cuatro escudos (media onza) y con ley de 875 milésimas. La figura femenina es similar a la grabada en la moneda conmemorativa de un thaler acuñada en Alemania (Bavaria) en 1835. La túnica de la mujer de la moneda alemana es sustituida por la india parada costarricense por una faldilla a lo americano, que aparece con detalle en la prueba de troquel (Figura 11 B) de la moneda de una onza (8 escudos) que no fue acuñada. La faldilla y las flechas recuerdan a las del genio de la libertad de la medalla guatemalteca de 1821 (Figura 2).

De igual forma que en la medalla de 1821 las nuevas monedas de oro incluyen un pedestal donde se lee: "15 de setiembre de 1821 ". No obstante, la india parada, símbolo de libertad y mezcla de detalles del Viejo y Nuevo Mundos destaca por su originalidad en medio de las monedas europeas y americanas de la época, en las que la efigie del gobernante de turno era el grabado principal y más frecuente. Las nuevas monedas de oro de la República de Costa Rica fueron acuñadas entre 1850 y 1864, año en que entró a regir el sistema decimal (1 Peso = 100 centavos). Tanto la encina en las monedas de plata con su mensaje de hospitalidad, como la elegante figura femenina en las monedas de oro, también pregonaban otras prioridades gubernamentales. El estímulo de la inmigración europea dio por resultado la llegada al país de exmilitares, artesanos, nuevos cafetaleros y científicos que traían a sus familias o establecieron aquí la propia (ver Hilje Quirós, 2013).

En la escogencia de los símbolos para las monedas de oro y de plata de la naciente República de Costa Rica tal vez influyeron costarricenses como don Manuel Carazo y el Dr. Castro, quienes tenían una amplia cultura y habían viajado por Europa. También podrían haber influido europeos como el ingeniero Johann Barth mencionado antes y el primer naturalista residente en Costa Rica, el danés Anders Sandoe Oersted. Tal como lo indica Hilje Quirós, Oersted ingresó al país en setiembre de 1846 y permaneció hasta 1848, viajó por el territorio nacional donde recolectó y luego describió especies de plantas y animales, dibujó el primer mapa detallado de la región central de Costa Rica y fue gran amigo de don Francisco María Oreamuno, el Jefe de Estado que en 1844 se negó a seguir siéndolo y que en 1847 fue Ministro de Hacienda por dos meses.

\section{Conclusión}

Desde tiempos antiguos las medallas y monedas fueron medios accesibles para transmitir mensajes concretos a los usuarios. La falta de medios de comunicación escrita y de personas capacitadas para leerlos servía de estímulo para grabar en esas piezas símbolos alusivos a las prioridades del gobierno y para dar a conocer sus gobernantes. Además, la acuñación de piezas conmemorativas de acontecimientos concretos y su puesta en circulación mediante celebraciones protocolarias complejas servía para reunir a la población, fomentar las relaciones sociales y la identificación del pueblo con ideales o con personajes específicos. La primera moneda conmemorativa de Costa Rica, la mariquita de 1847, así como los símbolos grabados en las monedas emitidas a partir de 1850 que pregonaron la forma de gobierno republicana, destacan en este contexto. 


\section{Agradecimientos}

Este trabajo tiene su origen en la ponencia presentada por los autores en el $\mathrm{II}^{\circ}$ Congreso Centroamericano de Numismática celebrado del 24 al 27 de setiembre del 2014 en el auditorio de los Museos del Banco Central de Costa Rica, Plaza de la Cultura. Agradecemos a Rafael Loáiciga, técnico del microscopio electrónico de barrido del Centro de Investigación en Estructuras Microscópicas (CIEMIC) de la Universidad de Costa Rica y a Sergio Aguilar, quien preparó las figuras y cuadros.

\section{Bibliografía}

Anónimo. (1948). Facsímile del Acta de Independencia de Centro América. Firmada en la ciudad de Guatemala el 15 de septiembre de 1821. Guatemala: Tipografía Nacional. 7 p.

Anónimo. (1978). Mentor Costarricense 1842-1846. Edición fascímil. Comisión Nacional de Conmemoraciones Históricas. San José: Oficina de Publicaciones de la Universidad de Costa Rica.

Buttrey, Theodore. (1967). Central America under the Mexican empire, 1822-1823. The American Numismatic Society Museum Notes 13, 231-250.

Chacón Hidalgo, Manuel. (2000). Del Estado a la República: las monedas y la política de Costa Rica (1821-1850). San José: Banco Central de Costa Rica.

Chacón Hidalgo, Manuel. (2012). Historia monetaria de Costa Rica en el periodo colonial (1502-1821). p 1-100. En R. Viales-Hurtado (Editor). Nueva Historia Monetaria de Costa Rica. De la colonia a la década de 1930. Colección Historia de Costa Rica. San José: Editorial de la Universidad de Costa Rica.

Dool, Donald. (2000). Microscope determines makeup of coins. World Coin News 27 (9), 54-55 / 58-60.

Fernández Guardia, Ricardo. (2006). Crónicas coloniales de Costa Rica. San José: Editorial Universidad Estatal a Distancia.

González Flores, Luis. (1934). Historia del café en Costa Rica. p. 475-508. En L. Bergna y A. Zen (Eds.). Anuario General de Costa Rica 1934. San José: Imprenta Borrasé Hnos.

Gurdián Montealegre, Raúl. (1996). Contribución al estudio de las monedas de Costa Rica. 2da edición. San José: Litografía e Imprenta Lil, S.A.

Hilje Quirós, Luko. (2013). Trópico agreste. La huella de los naturalistas alemanes en la Costa Rica del siglo XIX. Cartago: Editorial Tecnológica de Costa Rica.

Jara, Carlos. (2007). Central American Provisional and Provincial Mints. A research on the mints operative in Honduras, Nicaragua and Costa Rica between 1822-1825. Vol.1: History and coin attributions. Santiago, Chile: Editorial Medinensis.

Jovel, Roberto y Chacón, Manuel. (2014). Influencia de Francisco Morazán sobre la moneda centroamericana. San Salvador. El Salvador: Imprenta y Offset Ricaldone.

Lines, Jorge. (1971). Nuevas notas sobre la medalla conmemorativa de la Independencia del Reino de Guatemala el 15 de Setiembre de 1821. Revista de la Universidad de Costa Rica 31, 91-105.

Marr, Wilhelm. (2004). Viaje a Centroamérica. Traducción técnica y notas por Irene Reinhold del original Reise nach Central-Amerika (1863). San José: Editorial de la Universidad de Costa Rica.

Monge Pereira, Carlos. (2012). Proyecto de Ley. Declaratoria del día 29 de Octubre de 1821 como la fecha de la independencia de Costa Rica. Expediente 18.544. San José: Asamblea Legislativa de la República de Costa Rica.

Murillo, Jorge. (2004). Historia de las monedas de Costa Rica. Catálogo Numismático. San José: Editorial UNED-Banco Central de Costa Rica.

Sedwick, Daniel y Sedwick, Frank (2007). The practical book of cobs. $4^{\text {th }}$ edition. Florida. E.E.U.U: Daniel Frank Sedwick.

Temprano, Leo. (1993). Monedas de Colombia. Historia y Legislación 1811 a 1934. $5^{\text {ta }}$ ed. Bogotá. Colombia: Publicaciones Cultural Ltda. 
Vargas Zamora, José. (2011). 10 Centavos: Diez estudios sobre numismática costarricense. San José: Editorial de la Universidad de Costa Rica.

Vargas Zamora, José y Murillo Rivera, Jorge. (2013). El escudo del Estado de Costa Rica (1840) en el nuevo billete de 1.000 colones (2009). Revista Reflexiones 92 (1), 9-22.

Vargas Zamora, José. (2014). Una encina (Quercus sp.) en monedas y billetes de Costa Rica (1848-1948). Revista Reflexiones 93 (2), 35-53.

Vargas Zamora, José y Chacón Hidalgo, Manuel. (2016). Guía ilustrada de medallas de Costa Rica San José: Fundación Museos del Banco Central de Costa Rica-Master Litho. 
